IJSSP

$41,13 / 14$

16

Received 19 April 2021 Revised 24 June 2021 Accepted 24 June 2021

\section{The effect of parental roles on mental health outcomes of unemployment: a gender perspective}

\author{
Concetta Russo, Alessandra Decataldo and Marco Terraneo \\ Department of Sociology and Social Research, University of Milan-Bicocca, \\ Milan, Italy
}

\begin{abstract}
Purpose - This paper aims to investigate the extent to which family roles and settings can mediate the impact of unemployment on psychological well-being among Italian households.

Design/methodology/approach - Using the European Health Interview Survey data for 2015, the authors adopt linear regression models to evaluate the effect of family settings on the mental health outcomes of unemployment, in particular on the likelihood of developing depression. The latter is measured using the internationally validated Patient Health Questionnaire (PHQ-8). Since the gender gap in occupation has not ceased to exist in Italy, special attention is paid to the differences between males and females in the workforce. Findings - The results suggest that involvement in parental roles has a moderating influence on unemployment mental health outcomes among both men and women, although it has a higher effect on the female workforce. Moreover, the study shows that "not living far from the family of origin" could be considered a crucial moderating factor for both gender categories.

Originality/value - The novelty of this paper lies in its consideration of the implications the social definition of gender roles may have on gender-related expectancies and attributions in life domains, such as work and family.
\end{abstract}

Keywords Psychological well-being, Unemployment, Parental roles, Gender perspective, Italy Paper type Research paper

\section{Introduction}

In the aftermath of the 2008 global economic crisis, the World Health Organization (WHO) published a complete overview illustrating the paths through which economic downturns and societal changes impact individual mental health (WHO, 2011). WHO's overview leads one to consider socioeconomic variables either as "risk factors" or "protective" ones for people's psychological well-being. Being a part of a solid social network and having a secure and satisfying job, combined with government investment in welfare programs, are among the principal protective factors. On the other hand, social isolation, material deprivation, poor education, insecurity, job stress and unemployment are among the principal risk factors in the social economic domain.

To foster a better understanding of how some of these risks and protective factors interact with one another, social science research has commonly focused on studying the relationship between unemployment, social ties and their health-related consequences (Gore, 1978). Nevertheless, considering that families constitute individual intimate social contexts, the

(c) Concetta Russo, Alessandra Decataldo and Marco Terraneo. Published by Emerald Publishing Limited. This article is published under the Creative Commons Attribution (CC BY 4.0) licence. Anyone may reproduce, distribute, translate and create derivative works of this article (for both commercial and non-commercial purposes), subject to full attribution to the original publication and authors. The full terms of this licence may be seen at http://creativecommons.org/licences/by/4.0/legalcode
International Journal of Sociology and Social Policy Vol. 41 No. 13/14, 2021 pp. 16-33

Emerald Publishing Limited 0144-333X

DOI 10.1108/IJSSP-04-2021-0093 
mediating potential of family roles and settings has rarely been addressed by studies about the mental health outcomes of unemployment (Artazcoz et al., 2004).

This paper aims to address this literature gap by investigating the way in which family roles, in particular parental ones, mediate the impact of unemployment on psychological wellbeing among members of Italian households.

Using the European Health Interview Survey (EHIS) data for 2015, we adopt linear regression models to evaluate the effect of family settings on the mental health outcomes of unemployment, such as the likelihood of developing depression. Considering the gender gap in the Italian workforce, and the burden that the social definition of gender roles places on individuals by forging asymmetries in the distribution of family responsibilities, special attention will be paid to the differences between males and females in the workforce.

In the following pages, we first introduce the background of this study, exploring the main models of analysis of the unemployment impact on mental health. In the following section, we discuss the sociological literature on the interaction between family roles, employment status and psychological well-being. The functional model (Jahoda, 1982) along with the role enhancement hypothesis (Sieber, 1974) will serve as the theoretical framework of the analysis. We then briefly offer some insight on the Italian labor market and unemployment-related issues. After, we describe the dataset and the conducted analysis, showing how unemployed people who are involved in parental roles and/or live nearby their family of origin are less likely to be depressed according to the internationally validated Patient Health Questionnaire (PHQ-8), which is the chosen mental health scale for this study. Finally, we analyze the results by discussing how the cultural specificity of the Italian family model intervenes in the relation between employment status and self-evaluation.

\section{Theoretical framework}

Sociologists have long recognized that unemployment is an important factor influencing both physical and mental health (Nordenmark and Strandh, 1999; Dooley, 2003). Nevertheless, there is a lack of both theoretical models and empirical research on possible mediating mechanisms and moderating factors between unemployment and mental well-being (Ezzy, 1993; Puig-Barrachina et al., 2011). The most explored theoretical frameworks include the stress theory of unemployment, the social support model, the economic deprivation model and the functional model. The stress theory suggests applying a direct pathway to link uncertainty about one's future employment situation to an enhancement of stress, which not only impacts mental well-being but could also induce risky health behaviors, thus eroding physical health as well (Muntaner et al., 2010). The economic deprivation model focuses on how unemployment, by potentially causing financial distress, worsens the unemployed person's material living conditions, which could be associated with negative health outcomes (Bartley, 1994).

The functional model focuses on the "value" of employment per se, and its "function" in individual self-evaluation (Jahoda, 1982). Indeed, by threatening social status, self-esteem and self-evaluation (Ezzy, 1993), and by potentially limiting physical and mental activity, not to mention the use of one's skills (Bartley, 1994), unemployment could also cause noneconomic losses that might have an impact on individuals' psychological well-being.

Finally, the social support model highlights how increased social isolation, precipitated by unemployment, could have either a direct influence on physical and mental health or an indirect one by deteriorating the buffering effect of social support (Benach et al., 2010).

Although the latter model considers the potential loss of one's social support network, it does not properly reflect on the mediating effects of individual intimate social contexts, such as the family, and the role that assuming family responsibilities could play in mitigating unemployment effects on psychological well-being (Artazcoz et al., 2004). For instance, the

Unemployment, family ties and mental health 
IJSSP

$41,13 / 14$

role enhancement hypothesis (Sieber, 1974) holds that when a problem arises in one role (e.g. work), another role (e.g. parenting) might provide alternative rewards. Consequently, the negative impact of losing one's job could affect people who have invested in their family responsibilities differently than people who have not (Artazcoz et al., 2004).

Existing analyses of the effects of unemployment on mental health often fail to adopt a gender-sensitive perspective (Decataldo and Ruspini, 2016). In fact, most of the studies that investigate unemployment have so far included only men (Artazcoz et al., 2004) or considered women in their role as "spouses" of unemployed men rather than as members of the workforce (Ström, 2003). Indeed, the few studies that have investigated unemployed women have so far proven inconclusive (Strandh et al., 2013). Thus, we aim to contribute to the literature on the relationship between unemployment and psychological well-being by considering the ways in which different cultural expectations regarding women's and men's family responsibilities result in the asymmetric division of informal care labor (both for offspring and older relatives), as literature has extensively shown (Lewis, 2009; Manzo and Minello, 2020), as well as how those expectations could implicate a gendered impact of job loss on psychological well-being. Indeed, parental roles and family care responsibilities in general, insofar as they contribute to positive self-evaluation, could have different weights for males and females in the workforce in moderating the impact of unemployment on mental health (Artazcoz et al., 2004; Strandh et al., 2013). Furthermore, scholars consider a poor work-life balance as a work-related stressor associated with health problems. Work-life balance support varies according to welfare state regime (Den Dulk and Van Doorne-Huiskes, 2007). Studies have found that Scandinavian countries provide the most extensive national work-life policies, whereas in other European countries, especially in Southern (which includes Italy) and Eastern welfare regimes, work-life balance support mainly depends on help from relatives or friends (Lunau et al., 2014).

Stemming from this theoretical framework, this study aims to use nationally representative data to investigate whether family settings moderate the impact of job loss on mental health, decreasing depression among unemployed people in Italy. To analyze the ways in which unemployment and mental health interact, we adopt the functional model (Jahoda, 1982). This model was recently found the most successful in explaining the links between unemployment and ill-health (see, e.g. Janlert and Hammarström, 2009), and is also commonly applied to compare the employed to the unemployed and to those outside the labor force, i.e. students, homemakers, retirees (Paul and Batinic, 2010). Indeed, drawing on Freud's description of work as the most enduring tie to reality for individuals, Jahoda recognized five psychological functions crucial for the self-concept that could be entirely satisfied only by working: time structure, social contacts, participation in collective purpose, regular activity and status and identity (Jahoda, 1982).

Furthermore, following the role enhancement hypothesis, participation in several roles enhances individuals' coping ability and reduces the impact of possible negative outcomes deriving from one of the roles (Sieber, 1974). As some scholars have recently argued (Greenhaus and Powell, 2006), both being employed and having a family provide individuals with core resources, enhancing self-esteem and self-evaluation and corroborating social status to the extent that benefits from one such domain positively influences individuals in the other. For instance, workers with children "may develop increased levels of patience from their parenting role and improve their working relationships with colleagues and subordinates" (Greenhaus and Powell, 2006, p. 83). Our working hypothesis is that some of these functions can also be found in the bearing of parental responsibilities, thus indirectly moderating the effects of unemployment on psychological well-being. Moreover, considering that, on the one hand, unemployment is unevenly distributed among the working population, disproportionately affecting women, and on the other, that in Italy, males and females tend to be differently engaged in informal family care (Manzo and Minello, 2020), gender will be one of the central elements of the analysis. 
Building on the aforementioned research, we define the following hypotheses:

H1. Family roles and settings moderate the effects of unemployment on psychological well-being.

Unemployment, family ties and mental health

H2. Family roles and settings do not have a gender-neutral impact - they have a more significant effect on unemployed females' psychological well-being than on that of unemployed males.

\section{Unemployment in Italy: a brief overview}

Unemployment is a prominent issue in Italy. According to the Organization for Economic Cooperation and Development (OECD) indicators, during the past 20 years, the Italian economy underwent three main recessions [1]: one from February 2001 to July 2003, one from March 2008 to May 2009 and another from June 2011 to April 2013 (ITARECD as of 2017). This sequence of financial hardships negatively impacted the national labor market, leading to alarmingly high national unemployment rates (Marino and Nunziata, 2017), which reached almost $12 \%$ in 2016, the third highest rate in the European Union after Greece and Spain, according to OECD statistics (2017).

Considering that long-term unemployment, which refers to people who have been unemployed for 12 months or more, can be particularly harmful for both physical and mental health (Herbig et al., 2013), it is also worth noting that the percentage of long-term unemployment comprised $58.3 \%$ of all unemployed Italian people in 2016 , having increased by $27.6 \%$ between 2008 and 2016 (Odone $e t$ al., 2018).

Meanwhile, the OECD also reports that the Italian Employment Protection Legislation (EPL) index decreased in the past 20 years, falling from 3.02 (1990) to 2.47 (2016) [2]. Indeed, several amendments were made to the Training and Employment National Contract and, more notably, two laws were introduced respectively in 2003 and 2012, which, on the one hand, had the effect of contributing to labor market precarization through the creation of new forms of flexible and fixed-term employment, and on the other, simplified the dismissal process for private employers. Moreover, as some scholars have argued (see, e.g. Reyneri, 2013), the process of disinvestment in welfare programs has made unemployment and job insecurity more difficult to bear and a source of greater fear and mental distress (Russo and Terraneo, 2020).

With regard to distribution, unemployment does not evenly affect the entire working population. Indeed, gender inequality has remained persistent in the Italian labor market, placing the country below the European Union (EU) average (Scherer and Reyneri, 2008), e.g. the current labor force participation rate for women in the chosen age class (35-64) is $56.6 \%$, compared to $78.4 \%$ for men (ISTAT, 2020). Meanwhile, women in Italy still tend to be responsible for the largest share of unpaid care-related work, holding the European record with an average of $4.5 \mathrm{~h}$ per day, compared to $1.5 \mathrm{~h}$ for Italian men (Manzo and Minello, 2020). This imbalance, as some authors have suggested (Cozza et al., 2008), has repercussions on wage equality, and women face more barriers than men in achieving positions of power. Both labor market gender inequality and informal care-related work imbalances suggest that a gender analysis is crucial to unravel how unemployment affects the mental health of men and women. Such an analysis may inform effective policies and foster a better understanding of how family roles are associated with male and female labor force participation.

\section{Data}

Drawing on the second wave of the EHIS (data 2015), this paper analyzes the function of parental roles and/or living nearby one's family of origin in moderating the impact of 
IJSSP

$41,13 / 14$

20

unemployment on Italian workers' mental health. EHIS is a general population survey providing statistical information on health status, health determinants and healthcare activities in the EU, for which no broad and comparable data basis was previously available [3].

The Italian sample size counts 25,325 people. The survey gathered self-reported information on general health (e.g. morbidity, self-perceived health status, health related behaviors and use of health care services), as well as sociodemographic and employment-related data.

For the purpose of this paper, we analyzed a nationally representative sample of 9,328 individuals, including 5,311 males and 4,017 females aged 35-64. Of this sample, 1,355 males and 999 females were unemployed. We chose this age range to represent the adult labor force since 35 [4] is the most common age barrier for accessing youth benefits in Italy - e.g. stage and apprentice contracts are no longer available after this age. Meanwhile the retirement age is estimated at approximatively 65 years. Furthermore, according to a EUROSTAT report (2019), Italians move out of their parents' home at the average age of 30 and the average maternal age of first childbirth is 32 , which allows us to consider the chosen age range as appropriate for identifying family relations in adult life as well (Treas and Lawton, 1999).

\section{Method}

This paper uses two dimensions to identify parental roles and family settings: (1) the household structure, which is dichotomized into the condition of living in the same household with a partner/spouse and offspring versus the condition of living alone and/or without children; and (2) the geographical proximity to the respondent's family of origin. The latter dimension was captured through the question "Is your household located far from other family members?," which we considered a subjective measure, since no further indication of the concept "far/near" was provided in the questionnaire and the variable was binary (yes/ no). It is also worth mentioning that in the Italian version of the EHIS, the question was rubricated on the list of "household problems," and that living far from extended family was already assigned a negative value by the questionnaire design [5]. With regard to the aim of this study, this variable was meant to tackle the limit of considering parental roles from a strictly parents/young children perspective, aiming to explore the adult-children/parents perspective as well (Treas and Lawton, 1999).

Employment status was conceptually broken into two categories: unemployed and employed. Participants not currently working but actively seeking a job were considered unemployed in the survey.

Starting from these three variables (employment status, geographical proximity to the family of origin and household structure), we constructed an employment-family typology. First, to obtain the family-related living condition, we computed a dichotomous variable: (1) living alone or being in a couple without children and (2) being in a couple with children. This decision aimed to capture the effect of parental roles. Second, by crossing this new variable with geographical proximity to the extended family and employment condition, we obtained a typology with four types of employment and four types of unemployment. Both employed and unemployed were grouped as follows: (1) living near the family of origin and being in a couple with children, (2) living far from the family of origin and being in a couple with children, (3) living near the family of origin and living alone or in a couple without children and (4) living far from the family of origin and living alone or in a couple without children. This typology, called "employment-family groups," is the independent variable used in the regression models [6]; the "employed, living near the family of origin and being in a couple with children" (EMP_Near family_couple_with_child) population was considered the reference group, since per our theoretical hypothesis they hold the best conditions both in terms of family and employment status. Coherently with the recent applications of Jahoda's 
functional model and Sieber's enhancement hypothesis mentioned above, we acknowledge that other variables, such as "volunteering in the community," may enhance one's selfevaluation and contribute to better health outcomes in the case of job loss, but were not able to take them into consideration here. The descriptive statistics of the "employment-family groups" typology, as well as the other variables included in the study, are reported in Table A1 of the Appendix.

Our dependent variable is psychological well-being, measured using PHQ-8, which is established as a valid diagnostic and severity measure for depressive disorders (Kroenke et al., 2009). The PHQ-8 consists of eight of the nine criteria on which the DSM-IV diagnosis of depressive disorders is based. The ninth question in the DSM-IV, which assesses suicidal or self-injurious thoughts, was omitted because research indicates that the deletion of this question has only a minor effect on scoring, since thoughts of self-harm are fairly uncommon among the general population. The validity of the PHQ-8 has been established by several studies, and the results from it have been successfully compared with the results from the SF36 mental health items (Kroenke et al., 2001).

The PHQ-8 asks respondents how often in the past two weeks they experienced a particular depressive symptom, using a range that spans from 0 (never $-0-1$ day) to 3 (nearly every day - 12-14 days). The scores for each item are summed to produce a total score ranging from 0 to 24 points. A total score of $0-4$ represents no significant depressive symptoms. A total score of 5-9 represents mild depressive symptoms; 10 to 14, moderate; 15 to 19 , moderately severe; and 20 to 24 , severe (Kroenke et al., 2009). Since our aim is to assess the likelihood of depression, we considered respondents with scores approaching 4 as more likely to become depressed in the future.

\section{Analysis}

Linear regression models were used to estimate the role of family settings in moderating the impact of unemployment on mental health. First, Model 1 was calculated to test the premises of the study, demonstrating, through a linear regression, the associations between employment status and mental health measured using the PHQ-8 scale by gender.

Next, Model 2 was calculated to test whether the effect of unemployment on mental health varies across the group according to family setting. For the model, we used a set of control variables to obtain parameter estimates. We included two variables as predisposing factors (age and gender) to observe the impact of family settings on different age groups and genders. Two variables were included as enabling factors: (1) educational attainment, divided into three categories, "lower secondary or below," "upper secondary or post-secondary" and "tertiary"; and (2) a measure of the net monthly household income by quintile. Finally, since numerous studies have stressed the difference between macro-regional areas in Italy (North, Center and South) in terms of both employment patterns (Alesina et al., 2001) and intergenerational family ties (Di Giulio and Rosina, 2007), we also included geographical area of residence among the variables to control macro-regional-level heterogeneity.

Finally, in Model 3, the interaction effect of gender on employment-family relationship was estimated to observe the different impacts of family settings on the psychological wellbeing of males and females in the workforce, controlled for all the aforementioned variables (age class, educational attainment, household income and geographical area of residence).

The average marginal effects (AME) of our regressor on the outcome of all models were computed to make tabular and visual displays of regressions results intuitive (Leeper, 2017).

\section{Results}

Figure 1 shows the AME on Model 1, the associations between employment status and mental health measured by the PHQ- 8 scale, where the interaction between employment
Unemployment, family ties and mental health 


\section{IJSSP \\ $41,13 / 14$}

\section{2}

Figure 1.

Adjusted predictions of gender on employment status with $95 \%$ CIs

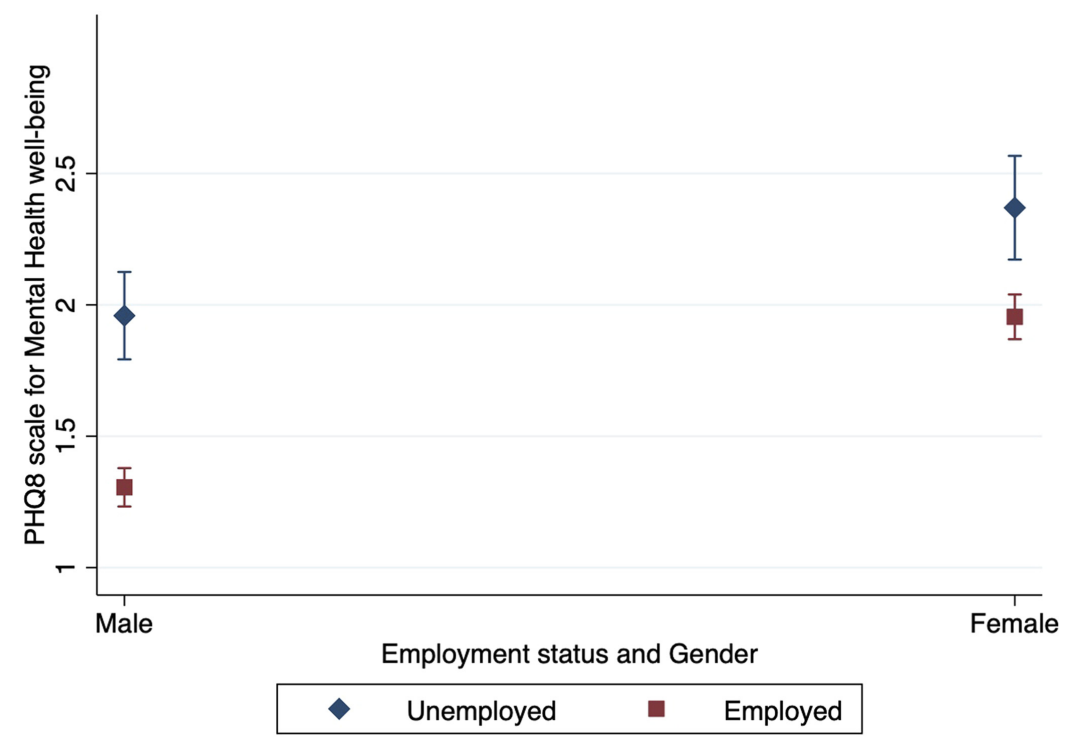

status and gender has been computed. The PHQ-8 scale ranges from 0 to 24 , but considering that "0" corresponds to "not depressed at all" and " 1 to 4" corresponds to "minimal depression," our workforce sample scored mainly in the 0-4 range. The graph shows that women scored worse than their male counterparts, and that both genders showed worse mental health in the unemployment condition. It is also interesting to observe that the differences between unemployed and employed males are higher than the corresponding differences among women. Indeed, unemployed men scored 1.95 (confidence interval (CI) 1.79-2.12), showing worse mental health than employed men, who scored 1.30 (CI 1.23-1.37). On the other hand, unemployed women scored 2.36 (CI 2.17-2.56), whereas employed women scored 1.95 (CI 1.86-2.03), demonstrating a smaller difference than their male counterparts. These preliminary results suggest that the theoretical premise that unemployment's impact on mental health is not gender-neutral needs further investigation.

Within this framework, the next step was to estimate, by applying a multilinear regression model, whether and to what extent family roles and settings moderate the effects of unemployment on people's mental well-being. The effect of the variable of interest specifically our measure of family roles and settings - is shown in Table 1 . We found that living with one's partner and offspring and having the family of origin nearby generally have a positive impact on mental health, but appear to have a more significant impact on unemployed people. Even after controlling for confounders, individuals coded as "unemployed, far from family of origin and not in living with a partner and/or children" scored 1.83 (CI 1.34-2.33) points higher on the PHQ-8 scale than our reference group, whereas e.g. unemployed people living with children and not far from family of origin scored just 0.46 (CI 0.22-0.69) points higher. Therefore, family roles and settings, as we have defined them, had a significant effect in moderating the impact of unemployment on people's well-being. Nevertheless, the two chosen family setting measures seem to have a different impact.

To visualize the results, Figure 2 illustrates the predictive margins of employment-family roles and settings interaction as indicated by the model. As can be seen by observing the difference in the score between Group 5 (UN_near_family_couple_with_child) and Group 6 (UN_FAR_family_couple_with_child), where the only distinction is perceived geographical 


\begin{tabular}{|c|c|c|c|c|}
\hline & Coef. & Std. err & $\mathrm{CI}$ & \multirow{10}{*}{$\begin{array}{l}\text { Unemployment, } \\
\text { family ties and } \\
\text { mental health }\end{array}$} \\
\hline \multicolumn{4}{|l|}{ Employment-family groups typology } & \\
\hline 1. EMP_Near_family_couple_with_child & Ref & & & \\
\hline 2.EMP_FAR_family_couple_with_child & 0.03 & 0.09 & $-0.14 ; 0.22$ & \\
\hline 3. EMP_near_family_NO_couple_with_child & 0.12 & 0.73 & $-0.02 ; 0.26$ & \\
\hline 4. EMP FAR family NO couple with child & 0.21 & 0.12 & $-0.017 ; 0.45$ & \\
\hline 5. UN_near_family_couple_with_child & 0.46 & 0.12 & $0.22 ; 0.69$ & \\
\hline 6. UN_FAR_family_couple_with_child & 1.15 & 0.20 & $0.75 ; 1.56$ & \\
\hline 7. UN_near_family_NO_couple_with_child & 0.73 & 0.15 & $0.44 ; 1.03$ & \\
\hline 8. UN_FAR_family_NO_couple_with_child & 1.83 & 0.25 & $1.34 ; 2.33$ & \\
\hline \multicolumn{5}{|l|}{ Gender } \\
\hline Male & Ref & & & \\
\hline Female & 0.66 & 0.05 & $0.55 ; 0.78$ & \\
\hline \multicolumn{5}{|l|}{ Education } \\
\hline Lower secondary or below & Ref & & & \\
\hline Upper secondary or post-secondary & -0.07 & 0.06 & $-0.24 ; 0.00$ & \\
\hline Tertiary & -0.29 & 0.88 & $-0.47 ;-0.12$ & \\
\hline \multicolumn{5}{|l|}{ Age class } \\
\hline $35-44$ & Ref & & & \\
\hline $45-54$ & 0.31 & 0.06 & $0.18 ; 0.43$ & \\
\hline $55-64$ & 0.58 & 0.07 & $0.43 ; 0.72$ & \\
\hline \multicolumn{5}{|l|}{ Net monthly income of the household } \\
\hline I quintile & Ref & & & \\
\hline II quintile & -0.09 & 0.09 & $-0.28 ; 0.09$ & \\
\hline III quintile & -0.32 & 0.09 & $-0.51 ;-0.13$ & \\
\hline IV quintile & -0.33 & 0.09 & $-0.52 ;-0.14$ & \\
\hline V quintile & -0.39 & 0.09 & $-0.58 ;-0.20$ & Table 1. \\
\hline \multicolumn{5}{|l|}{ Macro-region of residence } \\
\hline North & Ref & & & moderating effect of \\
\hline Center & -0.07 & 0.07 & $-0.21 ; 0.06$ & family roles and \\
\hline South & 0.03 & 0.06 & $-0.10 ; 0.16$ & settings on the mental \\
\hline Constant & 1.3 & 0.10 & $1.19 ; 1.60$ & health outcomes of \\
\hline$R^{2}$ & 0.04 & & & unemployment \\
\hline
\end{tabular}

distance from the extended family, we found that "living near [one's] family of origin" had a greater impact on unemployed groups than household structure, although both measures had a significant impact.

That being said, our interest was in comprehending if the impact of family roles and settings was gendered, since males and females in the workforce had different average scores in the first place and preliminary results seemed to suggest that unemployment had a greater impact on men than women (Figure 1). Thus, to shed light on the gender dimension, in Model 3, the linear regression estimated the interactive effect between gender and employment-family groups (complete data are available in the Appendix, Table A3). Figure 3 shows the effect of family roles and settings according to gender. We found that among employed groups, family settings only appear to have an impact on the female workforce. When comparing the group with the worst family setting conditions, per our theoretical premises, EMP_FAR_family_NO couple_with_child with our reference group (EMP_Near_family_couple_with_child), it is possible to observe that employed males show no significant differences, scoring respectively 1.25 (CI 0.91-1.59) and 1.30 (CI 1.20-1.40). On the other hand, their female counterparts show a slight difference, since the 
IJSSP

41,13/14

\section{4}

Figure 2.

Predictive margins of PHQ-8 scale $95 \%$ CIs, by typology

Figure 3.

Predictive margins of the PHQ-8 scale with $95 \%$ CIs, a comparison between males and females in the workforce
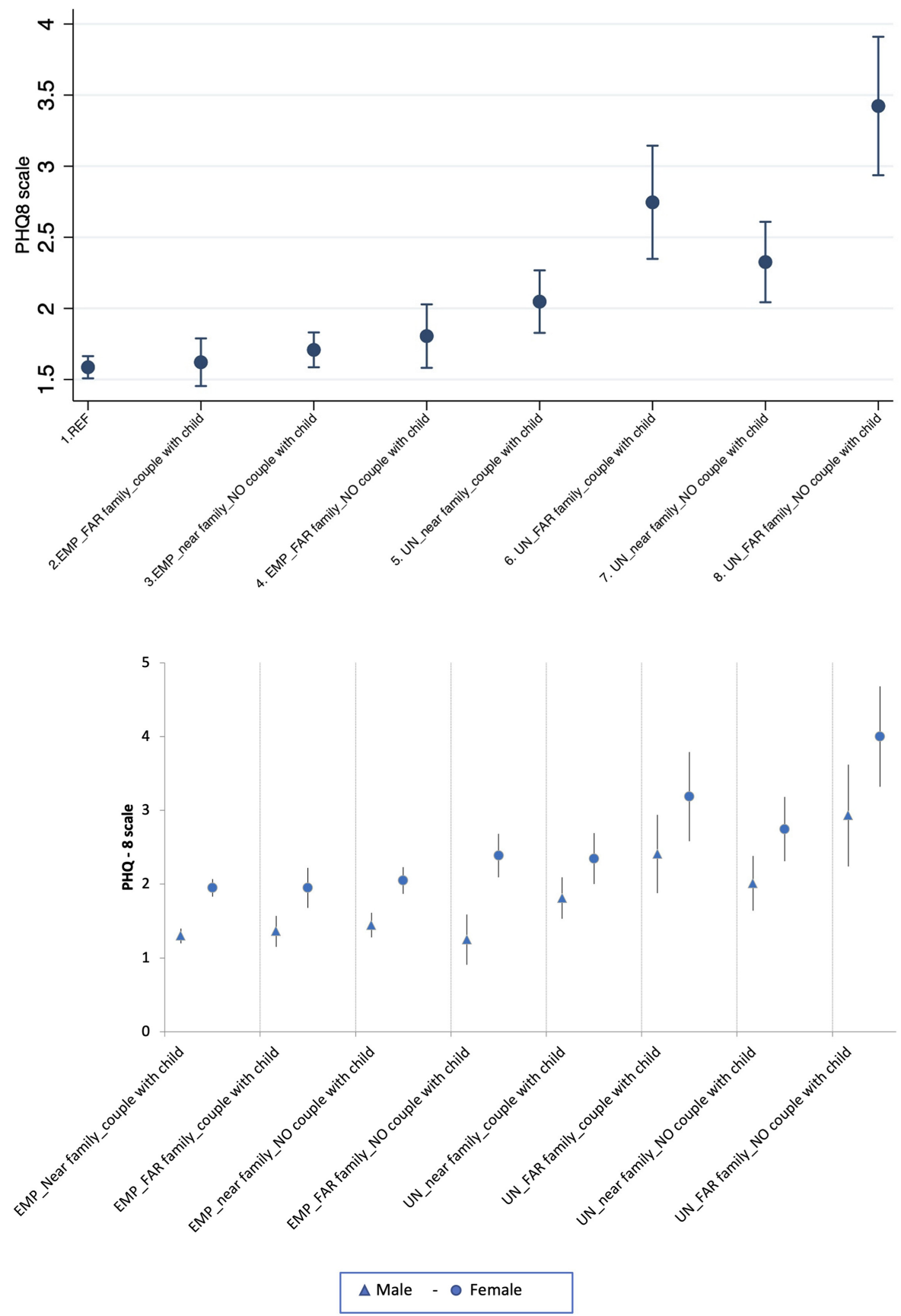
group with "far family and no children" scored 2.39 (CI 2.09-2.68), whereas the group with "near_family_and_children" scored 1.95 (CI 1.83-2.07).

The effect of family settings becomes more visible in the unemployed groups, suggesting that among unemployed females family setting has a greater impact than among unemployed males. Indeed, comparing the unemployed groups with the best family settings to those with the worst family settings, males scored 1.81 (CI 1.53-2.09) and 2.93 (CI 2.24-3.62) respectively, whereas females scored 2.35 (CI 2-2.69) and 4.00 (CI 3.32-4.68), respectively, meeting the threshold for "mild depression" with their higher scores (PHQ-8 > 4).

Moreover, household structure appears to worsen the effect of unemployment on females in the workforce more than it does on males in the workforce. As the figure shows, in the group "unemployed, living near the family of origin and living alone or in a couple without children," women scored 2.75 (CI 2.31-3.18), while their male counterparts scored 2.01 (CI 1.64-2.38). It is also worth noting that unemployed women living far from the family of origin and without children had a worse score than their male counterparts, scoring 4.00 (CI 3.324.68 ) and 2.93 (CI 2.24-3.62), respectively.

\section{Discussion}

The relationship between employment condition and mental health has proven too complex to be encompassed by the simplistic idea that having a steady job has a positive impact on mental health and having precarious employment or losing a job has a negative one (Ezzy, 1993; Reyneri, 2013). As a matter of fact, although many scholars have found that unemployment usually has a negative impact on one's general and mental health (Jahoda, 1982; Bartley, 1994; Dooley, 2003; Paul and Batinic, 2010; Herbig et al., 2013), there is a great array of factors that can play a role not only in moderating but sometimes in subverting that impact (Benach et al., 2010; Carlson et al., 2011). Thus, comprehension of the complex relationship between employment status and self-evaluation has proven crucial in fostering a better understanding of the factors that come into play when we evaluate the effects of losing a job and of being unemployed on one's mental health (Jahoda, 1982; Ezzy, 1993; Janlert and Hammarström, 2009; Paul and Batinic, 2010).

Indeed, if it is true that work encompasses a person's human side, being part of a family can be considered an equally central aspect of a person's life experience. For this reason, the concept of work-family balance has gained attention in social science (Gareis et al., 2009) and its relationship with psychological well-being is considered significant (Jaga et al., 2013). Nonetheless, the role of family settings and parental relations in contrasting the relative effects of unemployment on mental health has been so far under-investigated (Artazcoz et al., 2004; Strandh et al., 2013).

In an attempt to address this gap in the sociological approach to the analysis of unemployment, our study investigates the moderating effect of family roles and settings on unemployment mental health outcomes, following the scholars who maintain that being invested in more than one role (e.g. employee, partner, parent and so on) has a positive impact on psychological well-being (Carlson et al., 2011). The results suggest that (1) being in a stable couple relationship and parenting moderate the negative effects of unemployment on the mental health of both males and females in the workforce, but that (2) it has a greater impact on unemployed women and that (3) not living far from the extended family is also a crucial moderating factor for both gender categories.

(1) The fact that being engaged in parental roles acts as a buffer could be explained in the framework of role (Sieber, 1974; Greenhaus and Powell, 2006) and identity theories (McCall and Simmons, 1966; Rosenberg, 1986), which suggest that there are a range of
Unemployment, family ties and mental health 
IJSSP

$41,13 / 14$

\section{6}

role performances associated with positive self-evaluation. Thus, if job loss can be perceived as an abrupt change of social status that threatens the individual concept of self to the detriment of psychological health (Ezzy, 1993), being invested in another meaningful role-such as parent - mitigates the negative impact of unemployment on self-evaluation. Moreover, drawing from Jahoda's (1982) functional model, which describes unemployment in terms of lack of time structure, social purpose and meaningful activities, it is possible to consider parenting as being associated with those latent consequences as well (Strandh et al., 2013).

(2) From a gender perspective, our study found that being invested in a parental role has a more significant impact on women than on men, when comparing people of the same age and employment status, and especially when comparing women living far from their family of origin and without children with their male counterparts. To interpret this result, we ought to consider that adherence to stereotypical gender role responsibilities, where women are supposed to carry out the informal care labor and men are supposed to undertake the role of primary breadwinner, is still common in Italy (Manzo and Minello, 2020). That being said, and with the idea that when analyzing the impact of unemployment on individual mental health we should consider the concept of psychological well-being not only as a matter of individual traits but also as a social product (Ezzy, 1993), it is possible to understand how women might gain greater social legitimation from the role of parent than their male partners, thus allowing for a more positive self-evaluation in spite of job loss. This result is consistent with the results of a study that compared two European countries with different gender regimes, Ireland and Sweden - illustrating how the more males and females are considered equal in the labor force (with equal pay and no gender discrimination), and the more caring for children is considered a "parent task" and not a "mother task" - the more similar the effects of unemployment on mental health are for both males and females (Strandh et al., 2013).

On the other hand, we must consider that in Italy, this result could also be linked to a sort of reverse effect of the reason for job loss, since ISTAT data show that around $20 \%$ of working mothers left or lost their job after childbirth (ISTAT, 2020) due to the difficulty of reconciling child care with work duties and the scarce availability of childcare services (Luppi and Arpino, 2016).

(3) The importance of "not living far from the family of origin" as a moderating factor could read as particularly surprising, given the fact that the youngest group of the workforce (15-34) was excluded from this study. Nonetheless, the relevance of this factor should be observed considering the cultural specificity of Italian family ties (Dalla Zuanna and Micheli, 2004), where intergenerational relations (between parents and adult children) remain strong well into adulthood and family is considered an important instrument of social protection. Indeed, Mediterranean countries are considered the domain of the "strong family" model, where strong ties between parents and adult children not only favor forms of economic solidarity but also contribute to forging mentality and social norms (Barbagli et al., 2003). It should also be noted that, although rising female labor market participation in the past 20 years contributed to an increased demand for long-term care services for the elderly, due to social norms related to family responsibility, the institutionalization of dependent older relatives tends to be stigmatized, and many Italians choose to take care of their elderly at home (Da Roit, 2010; Chiatti et al., 2013). Stemming from these considerations, the key role not living far from extended family plays in moderating the impact of unemployment on psychological well-being could 
suggest that strong blood ties still constitute not only an important social network (Huffman et al., 2015), but also a factor that contributes to the possibility of maintaining a positive self-evaluation despite having experienced a self-concept threatening event such as job loss.

Overall, these results highlight how "the work environment and the distribution of healththreatening working conditions are rooted in the wider economic, political and social context" (Lunau et al., 2014, p. 422). This means, among other things, that different welfare state support policies, such as measures for tackling unemployment, reconciling work and family life or expanding childcare services, might mitigate the adverse effects of work-related factors on individual well-being. Considering, as widely discussed above, the relationship between labor market participation, family characteristics and mental health in Italy, the implementation of social policies comparable to those of the Scandinavian welfare state (Den Dulk and Van Doorne-Huiskes, 2007) would improve general mental health and reduce current inequalities between women and men.

Although geographical region of residence could be expected to play a role in the relevance of family ties - since scholars have pointed out the difference between macroregional areas of Italy (North, Center and South), both in terms of employment patterns (Alesina et al., 2001) and intergenerational family ties (Di Giulio and Rosina, 2007) - our results suggest that it does not. This could be explained by the fact that in Italy, the tendency to maintain strong ties with the family of origin is more common than in other European countries, regardless of national macro-regional area (Dalla Zuanna and Micheli, 2004), and that even in the most industrialized regions, familism has not yet ceased to play an important social and economic role (Ghezzi, 2015).

Finally, our findings suggest that the net monthly household income and level of education do not directly impact the relation between unemployment and psychological wellbeing, probably because unemployed people are a fairly homogeneous group, with low educational qualifications and low incomes. Therefore, there is too little heterogeneity to observe the impact of such variables.

\section{Conclusion}

The findings of our study suggest that unemployment is negatively associated with mental health, and that when family roles are considered, the patterns of association between unemployment and mental health become more evident: both being parents (living with partner/spouse and children) and living near extended family appear to have a protective effect for both women and men. Moreover, the results suggest that, due to dominant gender norms and institutions and the different socioeconomic roles occupied by men and women in Italy, the moderating effect of parenthood is gendered, concerning females in the workforce more than their male counterparts. Thus, the different patterns of participation of Italian men and women in both the labor market and family roles and responsibilities could be considered as contributing to producing and maintaining gendered differences in the relationship between unemployment and psychological well-being.

This study has four potential limitations. First, it did not use a longitudinal panel; therefore, we cannot establish how the respondents' employment status shift or changes in family relations impacted their psychological well-being over time. Second, the EHIS dataset does not contain a second validated scale for measuring mental health such as the SF-36 or the WHO-5. Thus, neither a comparison of results nor an examination of the concept of wellbeing from a different perspective was possible. Third, the sample size of the typology groups under study was small in some cases (e.g. unemployed with or without children living far from family of origin, respectively Groups 6 and 8 in our typology), which, although expected
Unemployment, family ties and mental health 
IJSSP $41,13 / 14$

for the chosen age range, could have led to biased estimates. Finally, due to the survey design, it was not possible to include non-binary gender identities or informal work settings in the analysis.

Despite these drawbacks, this study contributes to the debate on the relation between employment status and individuals' mental health by including both family roles and gender regime as moderating factors and, most importantly, by exploring often-overlooked female unemployment paths (Artazcoz et al., 2004; Strandh et al., 2013).

\section{Notes}

1. Economic consequences of the Covid-19 pandemic are not included in this analysis.

2. EPL index ranges from 0 (no protection) to 5 (maximum protection).

3. In Italy, EHIS was carried out by the Italian National Institute of Statistics (ISTAT) as a standalone survey.

4. According to ISTAT, young people are citizens aged between 15 and 34 years.

5. As we will argue further in the discussion section, in the Italian "familistic" welfare system, the extended family is still considered the main provider of care and welfare for children and dependent individuals (Da Roit, 2010; Chiatti et al., 2013).

6. Before setting the typology, we ran a one-way ANOVA to see whether there were differences in mental health across groups. The results, which were consistent with the hypothesis, can be found in Table A2 of the Appendix.

\section{References}

Alesina, A., Danninger, S. and Rostagno, M. (2001), "Redistribution through public employment: the case of Italy", IMF Staff Papers, Vol. 48 No. 3, pp. 447-473.

Artazcoz, L., Benach, J., Borrell, C. and Cortes, I. (2004), "Unemployment and mental health: understanding the interactions among gender, family roles, and social class", American Journal of Public Health, Vol. 94 No. 1, pp. 82-88.

Barbagli, M., Castiglioni, M. and Dalla Zuanna, G. (2003), Fare Famiglia in Italia, Il Mulino, Bologna.

Bartley, M. (1994), "Unemployment and ill health: understanding the relationship", Journal of Epidemiology and Community Health, Vol. 48 No. 4, pp. 333-337.

Benach, J., Muntaner, C., Solar, O., Santana, V. and Quinlan, M. (2010), Empleo, trabajo y desigualdades en salud: una visión global, Barcelona, Icaria.

Carlson, D.S., Grzywacz, J.G., Ferguson, M., Hunter, E.M., Clinch, C.R. and Arcury, T.A. (2011), "Health and turnover of working mother after childbirth via the work-family interface: an analysis across time", Journal of Applied Psychology, Vol. 96, pp. 1045-1054.

Chiatti, C., Di Rosa, M., Greco, C., Barbabella, F., Lamura, G., Melchiorre, M.G., Principi, A. and Santini, S. (2013), "Migrant care work for elderly households: trends and developments in Italy on the background of global developments", in Troisi, J. and Von Kondratowicz, H.J. (Eds), Ageing in the Mediterranean, Policy Press, Bristol, pp. 235-256.

Cozza, M., Murgia, A. and Poggio, B. (2008), "Traiettorie ed intrecci nelle storie di carriera di uomini e donne. Una lettura di genere delle transizioni tra lavoro e non lavoro", Sociologia del lavoro, Vol. 110, pp. 201-212.

Da Roit, B. (2010), Strategies of Care: Changing Elderly Care in Italy and The Netherlands, Amsterdam University Press, Amsterdam.

Dalla Zuanna, G. and Micheli, G. (2004), Strong Family and Low Fertility: A Paradox? New Perspectives in Interpreting Contemporary Family and Reproductive Behavior, Kluwer Academic, Berlin. 
Decataldo, A. and Ruspini, E. (2016), "Gender-sensitive data: the State of the Art in Europe", International Review of Sociology: Revue Internationale de Sociologie, Vol. 16 No. 3, pp. 407-423.

Den Dulk, L. and Van Doorne-Huiskes, A. (2007), "Social policy in Europe: its impact on families and work", in Crompton, R., Lewis, S. and Lyonette, C. (Eds), Women, Men, Work and Family in Europe, Palgrave Macmillan, Basingstoke, pp. 35-57.

Di Giulio, P. and Rosina, A. (2007), "Intergenerational family ties and the diffusion of cohabitation in Italy”, Demographic Research, Vol. 16, pp. 441-468.

Dooley, D. (2003), "Unemployment, underemployment, and mental health: conceptualizing employment status as a continuum", American Journal of Community Psychology, Vol. 32 Nos 1-2, pp. 9-20.

EUROSTAT (2019), “Age of young people leaving their parental household”, available at: https://ec. europa.eu/eurostat/statistics-explained/index.php?title=Age_of_young_people_leaving_their_ parental_household\&stable=0\&redirect $=$ no (accessed 19 December 2020).

Ezzy, D. (1993), "Unemployment and mental health: a critical review”, Social Science and Medicine, Vol. 37 No. 1, pp. 41-52.

Gareis, K.C., Barnett, R.C., Ertel, K.A. and Berkman, L.F. (2009), "Work-family enrichment and conflict: additive effects, buffering, or balance?", Journal of Marriage and Family, Vol. 71, pp. 696-707.

Ghezzi, S. (2015), "Familism as a context for entrepreneurship in Northern Italy", Human Affairs, Vol. 25 No. 1, p. 58.

Gore, S. (1978), "The effect of social support in moderating the health consequences of unemployment", Journal of Health and Social Behavior, Vol. 19 No. 2, pp. 157-165.

Greenhaus, J.H. and Powell, G.N. (2006), "When work and family are allies: a theory of work-family enrichment", Academy of Management Review, Vol. 31 No. 1, pp. 72-92.

Herbig, B., Dragano, N. and Angerer, P. (2013), "Health in the long-term unemployed", Deutsches Arzteblatt International, Vol. 110 Nos 23-24, p. 413.

Huffman, A.H., Culbertson, S.S., Wayment, H.A. and Irving, L.H. (2015), "Resource replacement and psychological well-being during unemployment: the role of family support", Journal of Vocational Behavior, Vol. 89, pp. 74-82.

ISTAT (2020), "Indagine rilevazione forze lavoro", available at: https://www.istat.it/it/archivio/8077 (accessed 19 December 2020).

ITARECD (2017), "OECD based recession indicators for Italy from the period following the peak through the trough", available at: https://fred.stlouisfed.org/series/ITARECD (accessed 24 September 2017).

Jaga, A., Bagraim, J. and Williams, Z. (2013), "Work-family enrichment and psychological health", $S A$ Journal of Industrial Psychology, Vol. 39 No. 2, pp. 1-10.

Jahoda, M. (1982), Employment and Unemployment: A Social Psychological Analysis, Cambridge University Press, Cambridge.

Janlert, U. and Hammarström, A. (2009), "Which theory is best? Explanatory models of the relationship between unemployment and health", BMC Public Health, Vol. 9, pp. 1-9.

Kroenke, K., Spitzer, R.L. and Williams, J.B. (2001), “The PHQ-9: validity of a brief depression severity measure”, Journal of General Internal Medicine, Vol. 16 No. 9, pp. 606-613.

Kroenke, K., Strine, T.W., Spitzer, R.L., Williams, J.B., Berry, J.T. and Mokdad, A.H. (2009), "The PHQ-8 as a measure of current depression in the general population", Journal of Affective Disorders, Vol. 114 Nos 1-3, pp. 163-173.

Leeper, T.J. (2017), "Interpreting regression results using average marginal effects with R's margins", in Reference Manual, Vol. 32, pp. 1-32.

Lewis, J. (2009), Work-family Balance, Gender and Policy, Edward Elgar Publishing, London.
Unemployment, family ties and mental health 
IJSSP $41,13 / 14$

Lunau, T., Bambra, C., Eikemo, T.A., van der Wel, K.A. and Dragano, N. (2014), "A balancing act? Work-life balance, health and well-being in European welfare states", European Journal of Public Health, Vol. 24 No. 3, pp. 422-427.

Luppi, F. and Arpino, B. (2016), "Childcare arrangements and mothers' satisfaction with work-family balance", RECSM Working Paper Series, 49.

Manzo, L.K.C. and Minello, A. (2020), "Mothers, childcare duties, and remote working under COVID-19 lockdown in Italy: cultivating communities of care”, Dialogues in Human Geography, Vol. 10 No. 2, pp. 120-123.

Marino, F. and Nunziata, L. (2017), The Labor Market in Italy 2000-2016, IZA World of Labor, Institute for the Study of Labor (IZA), Bonn, No. 407.

McCall, G.J. and Simmons, J.L. (1966), Identities and Interactions, The Free Press, New York.

Muntaner, C., Solar, O., Vanroelen, C., Martínez, J.M., Vergara, M., Santana, V., Castedo, A., Kim, I.-H., Benach, J. and EMCONET Network (2010), "Unemployment, informal work, precarious employment, child labor, slavery, and health inequalities: pathways and mechanisms", International Journal of Health Services, Vol. 40 No. 2, pp. 281-295.

Nordenmark, M. and Strandh, M. (1999), "Towards a sociological understanding of mental well-being among the unemployed: the role of economic and psychosocial factors", Sociology, Vol. 33 No. 3, pp. 577-597.

Odone, A., Landriscina, T., Amerio, A. and Costa, G. (2018), "The impact of the current economic crisis on mental health in Italy: evidence from two representative national surveys", The European Journal of Public Health, Vol. 28 No. 3, pp. 490-495.

Organisation for Economic Co-operation and Development [OECD] (2017), "Unemployment", available at: https://data.oecd.org/unemp/unemployment-rate.htm-indicator-chart (accessed 23 August 2017).

Paul, K.I. and Batinic, B. (2010), “The need for work: Jahoda's latent functions of employment in a representative sample of the German population”, Journal of Organizational Behavior, Vol. 31, pp. $45-64$.

Puig-Barrachina, V., Malmusi, D., Martínez, J.M. and Benach, J. (2011), "Monitoring social determinants of health inequalities: the impact of unemployment among vulnerable groups", International Journal of Health Services, Vol. 41 No. 3, pp. 459-482.

Reyneri, E. (2013), "Benessere e qualità dell'occupazione”, in Bordogna, L., Pedersini, R. and Provasi, G. (Eds), Lavoro, mercato, istituzioni. Scritti in onore di Gian Primo Cella, FrancoAngeli, Milan, pp. 194-208.

Rosenberg, M. (1986), Conceiving the Self, Krieger Publishing Company, Malabar.

Russo, C. and Terraneo, M. (2020), "Mental well-being among workers: a cross-national analysis of job insecurity impact on the workforce", Social Indicators Research, Vol. 152, pp. 421-442.

Scherer, S. and Reyneri, E. (2008), "Com'è cresciuta l'occupazione femminile in Italia: fattori strutturali e culturali a confronto", Stato e mercato, Vol. 28 No. 2, pp. 183-216.

Sieber, S.D. (1974), "Toward a theory of role accumulation", American Sociological Review, Vol. 39 No. 4, pp. 567-578.

Strandh, M., Hammarström, A., Nilsson, K., Nordenmark, M. and Russel, H. (2013), "Unemployment, gender and mental health: the role of the gender regime", Sociology of Health and Illness, Vol. 35 No. 5, pp. 649-665.

Ström, S. (2003), "Unemployment and families: a review of research", Social Service Review, Vol. 77 No. 3, pp. 399-430.

Treas, J. and Lawton, L. (1999), "Family relations in adulthood", in Sussman, M.B., Steinmetz, S.K. and Peterson, G.W. (Eds), Handbook of Marriage and the Family, Springer, Boston, pp. 425-438.

WHO (2011), "Impact of economic crises on mental health", available at: https://www.euro.who.int/_ data/assets/pdf_file/0008/134999/e94837.pdf (accessed 20 February 2021). 


\section{Appendix}

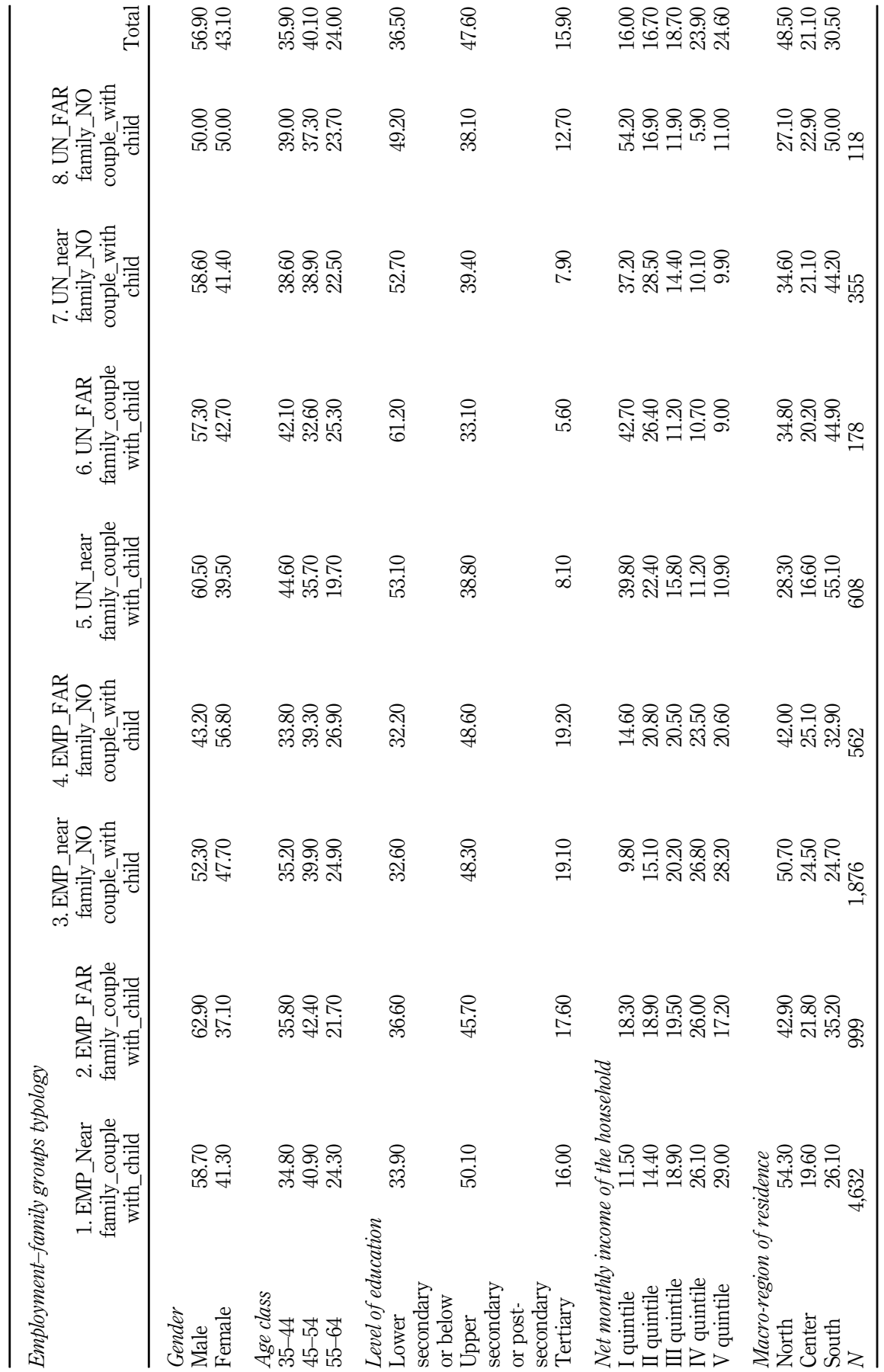

Unemployment, family ties and mental health
Table A1.

Descriptive statistics of the samples used in

analysis 
IJSSP

$41,13 / 14$

32

\begin{tabular}{llll}
\hline & Mean & Std. error & CI \\
\hline
\end{tabular}

Employment-family groups typology

1.EMP_Near_family_couple_with_child

2.EMP_FAR_family_couple_with_child

3. EMP_near_family_NO_couple_with_child

4.EMP_FAR_family_NO_couple_with_child

5. UN_near_family_couple_with_child

6. UN_FAR_family_couple_with_child

7. UN_near_family_NO_couple_with_child

8. UN_FAR_family_NO_couple_with_child

$\begin{array}{lll}1.55 & 0.03 & 1.48 ; 1.62 \\ 1.59 & 0.07 & 1.44 ; 1.74 \\ 1.70 & 0.06 & 1.57 ; 1.82 \\ 1.90 & 0.11 & 1.67 ; 2.13 \\ 2.13 & 0.12 & 1.88 ; 2.38 \\ 2.90 & 0.32 & 2.26 ; 3.53 \\ 2.45 & 0.19 & 2.07 ; 2.83 \\ 3.62 & 0.46 & 2.71 ; 4.53\end{array}$

results for the group typology

Table A3.

Model 3 interaction effect between gender and employmentfamily groups

\begin{tabular}{|c|c|c|c|}
\hline & Coef. & Std. error & $\mathrm{CI}$ \\
\hline $\begin{array}{l}\text { Employment-family groups typology } \\
\text { 1. EMP_Near_family_couple_with_child_MALE } \\
\text { 2. EMP_FAR_family_couple_with_child_MALE } \\
\text { 3. EMP_near_family_NO_couple_with_child_MALE } \\
\text { 4. EMP_FAR_family_NO_couple_with_child_MALE } \\
\text { 5. UN_near_family_couple_with_child_MALE } \\
\text { 6. UN_FAR_family_couple_with_child_MALE } \\
\text { 7. UN_near_family_NO_couple_with_child_MALE } \\
\text { 8. UN_FAR_family_NO_couple_with_child_MALE } \\
\text { 1. EMP_Near_family_couple_with_child_FEMALE } \\
\text { 2. EMP_FAR_family_couple_with_child_FEMALE } \\
\text { 3. EMP_near_family_NO_ccuple_with_child_FEMALE } \\
\text { 4. EMP_FAR_family_NO_couple_with_child_FEMALE } \\
\text { 5. UN_near_family_couple_with_child_FEMALE } \\
\text { 6. UN_FAR_family_couple_with_child_FEMALE } \\
\text { 7. UN_near_family_NO_couple_with_child_FEMALE } \\
\text { 8. UN_FAR_family_NO_couple_with_child_FEMALE }\end{array}$ & $\begin{array}{r}\text { Ref } \\
0.05 \\
0.14 \\
-0.05 \\
0.50 \\
1.11 \\
0.70 \\
1.63 \\
0.65 \\
0.64 \\
0.74 \\
1.08 \\
1.04 \\
1.88 \\
1.44 \\
2.69\end{array}$ & $\begin{array}{l}0.11 \\
0.10 \\
0.18 \\
0.15 \\
0.27 \\
0.19 \\
0.35 \\
0.08 \\
0.14 \\
0.10 \\
0.15 \\
0.18 \\
0.31 \\
0.22 \\
0.35\end{array}$ & $\begin{array}{r}-0.17 ; 0.29 \\
-0.05 ; 0.34 \\
-0.40 ; 0.30 \\
0.20 ; 0.80 \\
0.57 ; 1.64 \\
0.32 ; 1.09 \\
0.93 ; 2.32 \\
0.49 ; 0.80 \\
0.35 ; 0.94 \\
0.54 ; 0.95 \\
0.76 ; 1.39 \\
0.68 ; 1.40 \\
1.27 ; 2.49 \\
0.99 ; 1.88 \\
2.00 ; 3.39\end{array}$ \\
\hline $\begin{array}{l}\text { Education } \\
\text { Lower secondary or below } \\
\text { Upper secondary or post-secondary } \\
\text { Tertiary }\end{array}$ & $\begin{array}{c}\text { Ref } \\
-0.12 \\
-0.30\end{array}$ & $\begin{array}{l}0.06 \\
0.08\end{array}$ & $\begin{array}{l}-0.24 ; 0.00 \\
-0.47 ;-0.12\end{array}$ \\
\hline $\begin{array}{l}\text { Age class } \\
35-44 \\
45-54 \\
55-64\end{array}$ & $\begin{array}{c}\text { Ref } \\
0.31 \\
0.57\end{array}$ & $\begin{array}{l}0.06 \\
0.07\end{array}$ & $\begin{array}{l}0.18 ; 0.43 \\
0.43 ; 0.72\end{array}$ \\
\hline $\begin{array}{l}\text { Net monthly income of the household } \\
\text { I quintile } \\
\text { II quintile } \\
\text { III quintile } \\
\text { IV quintile } \\
\text { V quintile }\end{array}$ & $\begin{array}{l}\text { Ref } \\
-0.09 \\
-0.31 \\
-0.32 \\
-0.38\end{array}$ & $\begin{array}{l}0.09 \\
0.09 \\
0.09 \\
0.09\end{array}$ & $\begin{array}{l}-0.28 ; 0.09 \\
-0.51 ;-0.12 \\
-0.51 ;-0.13 \\
-0.57 ;-0.19\end{array}$ \\
\hline $\begin{array}{l}\text { Macro-region of residence } \\
\text { North } \\
\text { Center } \\
\text { South } \\
\text { Constant }\end{array}$ & $\begin{array}{c}\text { Ref } \\
-0.07 \\
0.03 \\
1.4\end{array}$ & $\begin{array}{l}0.07 \\
0.06 \\
0.10\end{array}$ & $\begin{array}{r}-0.21 ; 0.06 \\
-0.09 ; 0.16 \\
1.19 ; 1.60\end{array}$ \\
\hline
\end{tabular}

Ref

$$
0.14
$$

1.11

0.70

0.64

0.74

1.88

1.44

Ref

Lower secondary or below

Upper secondary or post-secondary

Tertiary

0.06

$-0.24 ; 0.00$

$-0.30$

Ref

0.31

0.06

$0.18 ; 0.43$

$45-54$

Ref

$-0.31$

0.09

$-0.51 ;-0.12$

$-0.51 ;-0.13$

IV quintile

Macro-region of residence

South
$-0.09 ; 0.16$ 


\section{About the authors}

Concetta Russo is a PhD Anthropologist and a Postdoctoral Fellow in Sociology and Social Research. Her first monograph is an ethnographic study of a Mental Health Community Center in la Habana, which investigates how the Cuban political and economic model influences both the concept of psychological well-being and the related treatments. Her current research topics are the impact of employment status on psychological well-being and the relationship between job insecurity and fertility decisions. Concetta Russo is the corresponding author and can be contacted at: concetta.russo@unimib.it

Alessandra Decataldo is an Associate Professor in Sociology and Social Research at the University of Milan Bicocca. She is a member of the Board of the Italian Sociological Association (AIS). She is currently coordinating the Milano Bicocca unit of the Research Project of Relevant National Interest (PRIN) "Evaluating the School-Work Alternance: a longitudinal study in Italian upper secondary schools"; furthermore, she is the Principal Investigator of the research project "Voicing preterm parents' experiences. A multidisciplinary study to set neonatal practices and enhance families' wellbeing (ParWelB)" funded by Fondazione Cariplo.

Marco Terraneo, $\mathrm{PhD}$, is fixed-term Research Assistant in Sociology of Health at the University of Milano-Bicocca of Milan and Adjunct Professor of Public Health at the University of Ca' Foscari of Venice. From 2016 to 2019, he was a member of the Board of Italian Sociological Association, Section of Sociology of Health and Medicine. His main research interests include social and health inequalities, deprivation and dimensions of social stratification.
Unemployment, family ties and mental health

For instructions on how to order reprints of this article, please visit our website: 